\title{
The impact of vitamin D status on hungry bone syndrome after surgery for primary hyperparathyroidism
}

\author{
Reto Martin Kaderli',2, Philipp Riss', Daniela Dunkler ${ }^{3}$, Peter Pietschmann ${ }^{4}$, Andreas Selberherr', \\ Christian Scheuba' and Bruno Niederle ${ }^{1}$
}

'Section of Endocrine Surgery, Division of General Surgery, Department of Surgery, Medical University of Vienna, Vienna, Austria, ${ }^{2}$ Department of Visceral Surgery and Medicine, Inselspital, Bern University Hospital, University of Bern, Bern, Switzerland, ${ }^{3}$ Section for Clinical Biometrics, Centre of Medical Statistics, Informatics and Intelligent Systems (CeMSIIS), Medical University of Vienna, Vienna, Austria, and ${ }^{4}$ Department of Pathophysiology and Allergy Research, Centre for Pathophysiology, Infectiology and Immunology, Medical University of Vienna, Vienna, Austria

Correspondence should be addressed to R M Kaderli

Email

reto.kaderli@insel.ch

\begin{abstract}
Objective: Prolonged hypocalcemia but normal intact parathyroid hormone (iPTH) levels after surgery for primary hyperparathyroidism (PHPT) are referred to as 'hungry bone syndrome' (HBS). The aim was to evaluate preoperative risk factors for HBS with a focus on the impact of 25-hydroxyvitamin D (25(OH)D) deficiency.

Design: Patients having undergone initial successful surgery for sporadic PHPT within 6 years were considered for retrospective analysis.

Methods: A total of 385 patients were evaluated, of whom 33 (8.6\%) developed HBS influencing negatively the postoperative bone metabolism. All patients underwent biochemical evaluations two days before parathyroid surgery and were followed biochemically on a daily basis in the first postoperative week and thereafter at 8 weeks and 6 months.

Conclusions: No relationship was established between preoperative 25(OH)D deficiency and HBS. The only significant risk factor for HBS in multivariable analysis was high levels of preoperative iPTH. As HBS therefore cannot be predicted preoperatively, we recommend a consistent postoperative calcium and vitamin D supplementation to improve the bone metabolism.
\end{abstract}

\section{Introduction}

Primary hyperparathyroidism (PHPT) is a common endocrine disorder with an incidence of approx. 90 per 100000 patient-years (1). It is defined by elevation of serum calcium (Ca) due to an inappropriate elevation or unsuppressed intact parathyroid hormone (iPTH), which leads to the absorption of $\mathrm{Ca}$ from bone via increased osteoclastic activity and reabsorption of $\mathrm{Ca}$ in the renal tubules (2). A single parathyroid tumor is the most frequent cause of PHPT, whereas multiple gland disease is less common (2). Surgery involving adequate resection of hypersecreting tissue is the treatment of choice, resulting
C 2017 European Society of Endocrinology Printed in Great Britain in an intraoperative iPTH decay of $\geq 50 \%$ from a defined 'baseline' level before skin incision within $10 \mathrm{~min}$ after excision ('Vienna Criterion') (3). iPTH reaches its lowest level on the first postoperative day with rapid subsequent recovery, while serum Ca decreases more slowly with the lowest levels between the second and third day $(4,5)$.

A severe and prolonged hypocalcemia despite normal or even elevated levels of iPTH due to a rapid increase of bone formation is called 'hungry bone syndrome' (HBS) (6). It should be treated by $\mathrm{Ca}$ and vitamin D supplementation (6). The underlying reason is assumed 
to be the normalization of high circulating iPTH levels, followed by enhanced bone formation with increased skeletal Ca requirement. Risk factors being discussed for HBS are advanced age, higher preoperative serum Ca, iPTH, alkaline phosphatase (ALP) and osteocalcin, as well as decreased serum magnesium and albumin levels $(6,7)$. Previous studies have examined the relationship between adenoma size and weight and postoperative serum $\mathrm{Ca}$ with conflicting results $(8,9)$.

Depleted levels of 25-hydroxyvitamin D (25(OH)D), which most accurately reflect vitamin D3 insufficiency (10), have been suggested to be a risk factor for the development of HBS: Low levels of 1,25-dihydroxyvitamin D (1,25(OH)2D), its activated endogenous variant, might be related to decreased absorption of $\mathrm{Ca}$, followed by a poor mineralization of the skeleton (11). Two studies found an association between preoperative $25(\mathrm{OH}) \mathrm{D}$ deficiency and hypocalcemia within the first postoperative week by asking the patients about the occurrence of hypocalcemic symptoms; yet, failed to measure serum Ca levels $(12,13)$. In a randomized-controlled trial, Rolighed et al. found no association between $25(\mathrm{OH}) \mathrm{D}$ and postoperative serum Ca level (14).

On the other hand, deficiency of $25(\mathrm{OH}) \mathrm{D}$ is associated with reactive hyperparathyroidism and thus elevated postoperative iPTH levels: $(2,15) 25(\mathrm{OH}) \mathrm{D}$ blunts the calcemic effect of iPTH, and while 1,25(OH)2D has an antiproliferative effect on parathyroid cells, its deficiency directly increases iPTH secretion independent of other factors.

Besides one study investigating vitamin D supplementation among PHPT patients with low 25(OH)D levels (14), studies investigating the relationship between 25(OH)D deficiency and postoperative $\mathrm{Ca}$ and iPTH levels after removing a solitary parathyroid adenoma are lacking. In view of the discussion concerning perioperative vitamin D supplementation, the aim of the present study was to evaluate risk factors for HBS with a focus on the impact of preoperative $25(\mathrm{OH}) \mathrm{D}$ deficiency on peri- and postoperative Ca and iPTH levels.

\section{Subjects and methods}

\section{Patients}

For the purposes of this study, we considered patients who had undergone initial surgery for sporadic PHPT. All data were prospectively documented and retrospectively analyzed. Indication for surgery followed the guidelines of the American Association of Endocrine Surgeons
(16) and the 'Guidelines for the management of asymptomatic primary hyperparathyroidism' (17). In all patients, solitary parathyroid adenomas were removed under general anesthesia by focused parathyroidectomy, unilateral or bilateral neck exploration. The diagnosis of solitary parathyroid adenoma was predicted intraoperatively by the decline of iPTH in the serum of $\geq 50 \%$ below baseline ('Vienna Criterion' (3)) and postoperatively confirmed by the histological workup and long-lasting normalization of the parathyroid metabolism.

Based on the reference values of our laboratory, HBS was defined by an albumin-adjusted total serum Ca $<2.20 \mathrm{mmol} / \mathrm{L}$ and an $\mathrm{iPTH} \geq 15 \mathrm{pg} / \mathrm{mL}$ after postoperative day 4 (between postoperative days 5 and 7).

Patients with preoperative renal insufficiency (creatinine $>1.2 \mathrm{mg} / \mathrm{dL}$ in men and $>0.9 \mathrm{mg} / \mathrm{dL}$ in women; glomerular filtration rate $<90 \mathrm{~mL} / \mathrm{min}$ ), preoperative medication possibly influencing biochemical workup (vitamin D or Ca supplementation, calcimimetic agents, bisphosphonates, thiazide diuretics and steroids), parathyroid or thyroid reintervention, hyperthyroidism, multiple gland and hereditary disease (familial hypocalciuric hypercalcemia, multiple endocrine neoplasia) were excluded.

All patients gave informed consent to all diagnostic and therapeutic procedures. The prospective data collection and the retrospective analysis were approved by the Ethics Committee of the Medical University of Vienna (resolution number 1979/2015).

\section{Study protocol}

All patients underwent biochemical evaluations two days before parathyroid surgery and intraoperatively by PTH monitoring (3). Following the standardized study protocol, none of the patients took $\mathrm{Ca}$ or vitamin $\mathrm{D}$ supplementation three months or longer before surgery. All patients were hospitalized for one week and followed biochemically on a daily basis with a daily analysis of the study parameters in the first postoperative week and thereafter at 8 weeks and 6 months postoperatively.

Symptomatic patients (such as perioral paresthesia and tingling extremities) were supplemented after the diagnosis of an HBS (between postoperative day 5 and 7) with $\mathrm{Ca}$ and 25 -hydroxycholecalciferol (1000 mg/880IE) in combination with 1,25-dihydroxycholecalciferol (calcitriol, $0.25 \mu \mathrm{g}$ ) twice daily. Calcitriol was given to 
promote absorption of dietary Ca from the gastrointestinal tract and to increase renal tubular reabsorption of Ca.

\section{Biochemical analyses}

All measurements were performed at the central laboratory of the Medical University of Vienna using standard laboratory methods. The following parameters were evaluated two days before surgery: $\mathrm{Ca}$, ionized $\mathrm{Ca}(\mathrm{iCa})$, magnesium, creatinine, albumin, 25(OH)D, 1,25(OH)2D, ALP, iPTH, osteocalcin, C-terminal telopeptide of type I collagen (beta-crosslaps), procollagen type 1 amino-terminal propeptide (P1NP), bone-specific alkaline phosphatase (BAP) and testosterone. Ca excretion was measured after 24-h urine collection for $\mathrm{Ca}\left(24 \mathrm{hU}_{\mathrm{Ca}}\right)$. Creatinine was measured again on postoperative day one to exclude renal insufficiency due to postoperative circulatory disorders.

Ca, magnesium, creatinine, albumin and ALP were determined by a routine multianalyzer. iCa levels were measured with an ion-sensitive gas analyzer (Radiometer, Copenhagen, Denmark). Chemiluminescence immunoassays (DiaSorin, Saluggia, Italy) were used for $25(\mathrm{OH}) \mathrm{D}, 1,25(\mathrm{OH}) 2 \mathrm{D}$ and BAP. iPTH, serum markers of bone turnover (beta-crosslaps, osteocalcin P1NP) and testosterone were measured using electrochemiluminescence immunoassays (Roche Diagnostics).

\section{Bone mineral density (BMD)}

Areal bone mineral density measurements of the posteroanterior lumbar spine at $\mathrm{L}_{1}-\mathrm{L}_{4}\left(\mathrm{BMD}_{\text {lumb }}\right)$ and the left femoral neck $\left(\mathrm{BMD}_{\text {neck }}\right)$ were performed with dual-energy X-ray absorptiometry on a QDR-4500 scanner (Hologic Inc., Waltham, MA, USA). All measurements were conducted using the standard procedures recommended by the manufacturer.

\section{Statistics}

The data were prospectively documented and retrospectively analyzed. Continuous data are presented as median, 1st and 3rd quartile (interquartile range (IQR)) and categorical variables are given as absolute frequencies and percentages. Various preoperative parameters of patients with (group 1) and without (group 2) HBS are compared using either $t$-tests or Wilcoxon tests, depending on the distribution of the underlying continuous risk factor or chi-square tests.
Spearman correlation was used to assess the correlation structure among suspected preoperative risk factors.

Univariate, bivariate and multivariable logistic regression was used to assess the association between preoperative, potential risk factors and HBS. Right-skewed risk factors were log-transformed prior to analysis and the relative decrease in iPTH between the 'baseline' level before skin incision and the first postoperative day was grouped into three tertiles: 0-80, 80-90 and 90-100\%. For a unified presentation of the results (odds ratios (OR) with 95\% confidence intervals (CI)), we present ORs comparing a patient at the 33rd percentile of the respective continuous risk factor with another patient at the 66th percentile (reference).

A multivariable logistic regression model for HBS was devised based on the clinical relevance of potential risk factors and correlation among these risk factors. C-indices, which are equivalent to the area under the curve (AUC), are given to quantify the predictive performance. The c-index states the probability that a randomly chosen patient with HBS has a higher predicted risk than a randomly chosen patient without HBS, with a value of 1 representing perfect discrimination. Line diagrams with mean and one standard error of the mean visualize the progression of pre- and postoperative kinetics of $\mathrm{Ca}$ and iPTH. A boxplot shows the distribution of 25(OH)D two days before surgery according to the four seasons. Analysis of variance was applied to test for differences in $25(\mathrm{OH})$ $\mathrm{D}$ between the seasons. All available cases were used for each statistical model. Statistical significance was defined at a 2 -sided level of $P<0.05$. We used SAS, version 9.2 (2008; SAS Institute Inc, Cary, NC, USA) for analysis and $\mathrm{R}$, version 3.2.3 for figure preparation.

\section{Results}

\section{Study population}

Overall, 385 (277 (72.0\%) female and 108 (28.1\%) male) patients at a median age of 59.0 (IQR: 49.0, 68.0) years were included in the present study (Fig. 1).

By definition, HBS was documented in 33 (8.6\%) subjects (group 1). Compared to group 2 (patients without HBS), group 1 was significantly older (68.0 years (IQR: $63.0,73.0$ ) vs 58.0 years (IQR: $49.0,68.0$ ); $P=0.001$ ).

Preoperative biochemical parameters and BMD for patients in both groups are shown in Table 1.

Focused parathyroidectomy was performed in 162 (42.1\%), unilateral neck exploration in 89 (23.1\%) and bilateral neck exploration in 134 (34.8\%) patients. The 


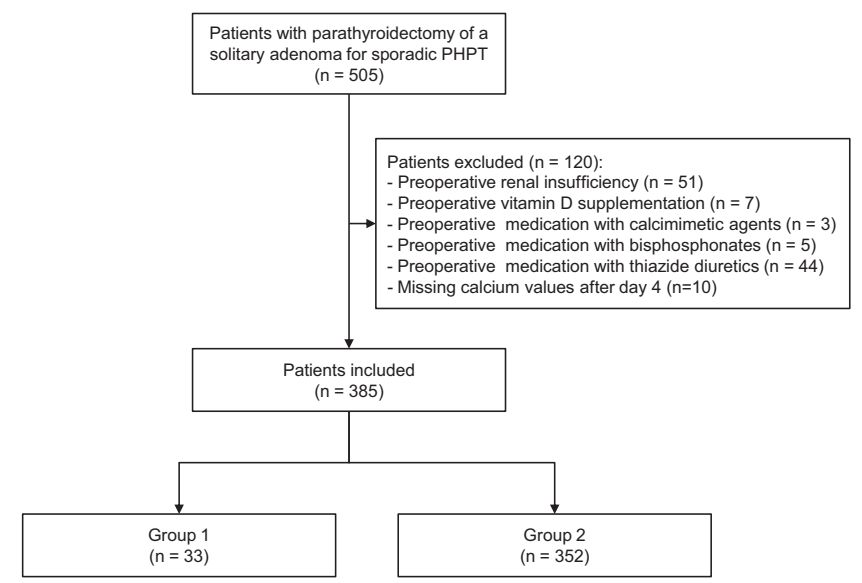

Figure 1

Flowchart of patients analyzed in the study period. Group 1: patients with hungry bone syndrome (HBS); group 2: patients without HBS.

median volume of surgically removed single adenoma was 4.8 (IQR: $2.5,10.4) \mathrm{cm}^{3}(15.1$ (IQR: $8.1,25.2) \mathrm{cm}^{3}$ in group 1 and 4.5 (IQR: $2.5,9.38) \mathrm{cm}^{3}$ in group 2 ; $P<0.001$ ). In $145(37.7 \%)$ patients, concurrent thyroid pathology required additional thyroid surgery with thyroidectomy in $78(20.3 \%)(13 / 33(39.4 \%)$ in group 1 and $65 / 352$ (18.5\%) in group $2 ; P=0.004)$ and hemithyroidectomy in
$67(17.4 \%)$ patients (5/33 (15.2\%) in group 1 and 62/352 (17.6\%) in group $2 ; P=0.721$ ).

One patient of group 2 developed persistent PHPT (i.e. $\mathrm{Ca}>2.55 \mathrm{mmol} / \mathrm{L}$; iPTH $>65 \mathrm{pg} / \mathrm{mL}$ longer than 6 months postoperatively). This subject was excluded from all statistical evaluations.

Permanent hypoparathyroidism (i.e. Ca $<2.20 \mathrm{mmol} / \mathrm{L}$; iPTH $<15 \mathrm{pg} / \mathrm{mL}$ longer than 6 months postoperatively) was documented in none of the patients.

Figures 2 and 3 show the pre- and postoperative kinetics of $\mathrm{Ca}$ and iPTH during the first 8 weeks.

\section{Correlation between preoperative risk factors for HBS}

25(OH)D correlated neither with iPTH $(r=-0.359)$, the median volume of the removed adenomas $(r=-0.221)$ nor with the serum markers of bone turnover ALP $(r=-0.176)$, osteocalcin $(r=-0.141)$, beta-crosslaps $(r=-0.051)$, P1NP $(r=-0.100)$ or BAP $(r=-0.217)$ in applying the Spearman test. Furthermore, no association was established between $25(\mathrm{OH}) \mathrm{D}$ and $\mathrm{BMD}_{\text {lumb }}(r=-0.045)$ as well as $\mathrm{BMD}_{\text {neck }}$ $(r=0.009)$.

Regarding the associations between serum markers of bone turnover, osteocalcin was strongly correlated with both beta-crosslaps $(r=0.783)$ and P1NP $(r=0.822)$ and

Table 1 Preoperative biochemical parameters and BMD of patients with (group 1) and without (group 2) HBS.

\begin{tabular}{|c|c|c|c|c|c|}
\hline Parameter & Unit & Reference range* & Group $1(n=33)$ median (IQR) & Group $2(n=352)$ median (IQR) & $P$ value \\
\hline $\mathrm{Ca}$ & $\mathrm{mmol} / \mathrm{L}$ & $2.20-2.55$ & $2.86(2.55 ; 2.96)$ & $2.70(2.62 ; 2.81)$ & 0.126 \\
\hline $\mathrm{iCa}$ & $\mathrm{mmol} / \mathrm{L}$ & $1.16-1.32$ & $1.49(1.40 ; 1.61)$ & $1.43(1.38 ; 1.49)$ & 0.012 \\
\hline Magnesium & $\mathrm{mmol} / \mathrm{L}$ & $0.66-1.07$ & $0.83(0.77 ; 0.87)$ & $0.84(0.80 ; 0.88)$ & 0.297 \\
\hline Albumin & $\mathrm{g} / \mathrm{L}$ & $34-52$ & $42.5(40.0 ; 45.3)$ & $45.3(43.2 ; 47.4)$ & $<0.001$ \\
\hline 25(OH)D & $\mathrm{nmol} / \mathrm{L}$ & $75-250$ & $35.6(22.9 ; 49.8)$ & $41.5(28.9 ; 55.4)$ & 0.240 \\
\hline $1,25(\mathrm{OH}) 2 \mathrm{D}$ & $\mathrm{pg} / \mathrm{mL}$ & $19.9-86.5$ & $53.5(41.0 ; 84.5)$ & $48.0(39.0 ; 68.5)$ & 0.184 \\
\hline ALP & $\mathrm{U} / \mathrm{L}$ & $30-130$ & $97(82 ; 125)$ & $78(63 ; 99)$ & $<0.001$ \\
\hline iPTH & $\mathrm{pg} / \mathrm{mL}$ & $15-65$ & $256(144 ; 385)$ & $110(88 ; 157)$ & $<0.001$ \\
\hline iPTH decrease (24h) & $\%$ & - & $95.7(91.5 ; 98.2)$ & $84.3(75.0 ; 92.0)$ & $<0.001$ \\
\hline Osteocalcin & $\mathrm{ng} / \mathrm{mL}$ & $11-46$ ** & $56.2(33.6 ; 99.2)$ & $36.3(26.5 ; 51.7)$ & 0.001 \\
\hline Beta-crosslaps & $\mathrm{ng} / \mathrm{mL}$ & $0.03-0.46 * *$ & $0.79(0.49 ; 1.14)$ & $0.65(0.46 ; 0.93)$ & 0.160 \\
\hline P1NP & $\mathrm{ng} / \mathrm{mL}$ & $16-92$ ** & $72.0(54.0 ; 130)$ & $59.0(42.0 ; 82.0)$ & 0.005 \\
\hline BAP & $\mathrm{ng} / \mathrm{mL}$ & $4.9-26.6 * \star \star$ & $19.8(17.3 ; 28.9)$ & $16.3(12.3 ; 21.9)$ & 0.007 \\
\hline Creatinine & $\mathrm{mg} / \mathrm{dL}$ & $>1.2$ (men), >0.9 (women) & $0.87(0.73 ; 0.99)$ & $0.78(0.68 ; 0.90)$ & 0.127 \\
\hline $24 \mathrm{hU}_{\mathrm{Ca}}$ & $\mathrm{mmol} / 24 \mathrm{~h}$ & $2.5-7.5$ & $5.35(3.45 ; 9.94)$ & $8.00(5.58 ; 10.80)$ & 0.010 \\
\hline $\mathrm{BMD}_{\text {lumb }}$ & SD & $\geq-1$ & $-2.1(-3.1 ;-0.5)$ & $-1.5(-2.4 ;-0.6)$ & 0.213 \\
\hline BMD $_{\text {neck }}$ & SD & $\geq-1$ & $-1.7(-2.0 ;-0.8)$ & $-1.1(-1.8 ;-0.3)$ & 0.006 \\
\hline Testosterone & & & & & \\
\hline Women $(n=277)$ & $\mathrm{ng} / \mathrm{mL}$ & $0.03-0.48 * * * *$ & $0.12(0.03 ; 0.24)$ & $0.15(0.08 ; 0.23)$ & 0.308 \\
\hline Men $(n=108)$ & $\mathrm{ng} / \mathrm{mL}$ & $1.9-8.4 * * * *$ & $5.07(4.08 ; 6.25)$ & $4.14(3.16 ; 4.79)$ & 0.013 \\
\hline
\end{tabular}



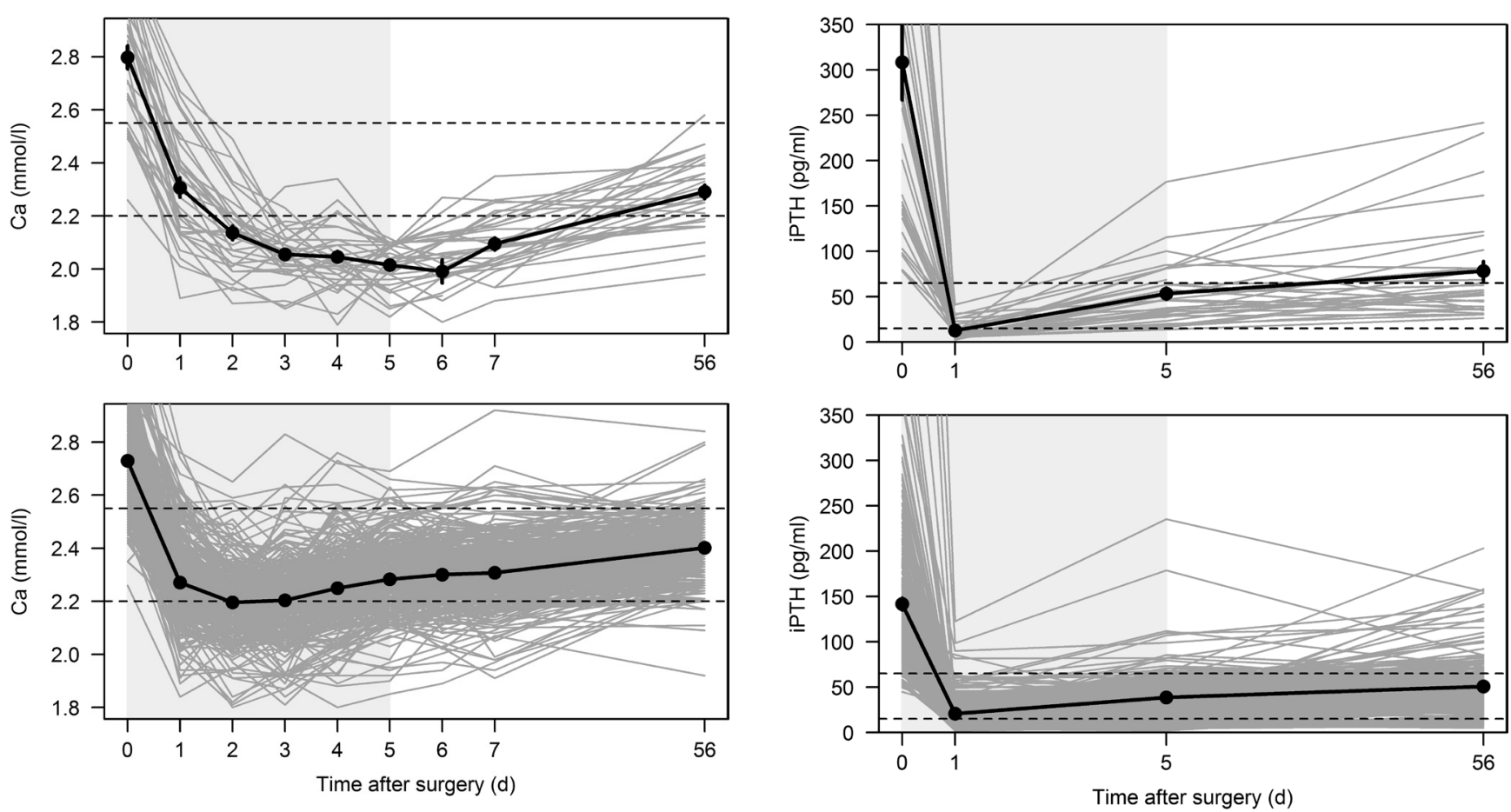

\section{Figure 2}

Pre- and post-operative kinetics of Ca levels among patients in group 1 (A) and group 2 (B). HBS was assessed at day 5. Gray lines: curves for each patient; black lines: mean curve for each group of patients (with indication of the standard error of the mean); dashed horizontal line: reference values for Ca. Preoperative Ca levels were cut off at $2.90 \mathrm{mmol} / \mathrm{L}$ for better visualization: 14 (42.4\%) patients in group 1 and $48(13.6 \%)$ in group 2 had Ca levels $>2.90 \mathrm{mmol} / \mathrm{L}$ (max. $3.20 \mathrm{mmol} / \mathrm{L}$ and $3.59 \mathrm{mmol} / \mathrm{L}$, respectively) at day 0 .

was positively correlated with ALP $(r=0.559)$ as well as BAP $(r=0.611)$. BMD $\mathrm{Bumb}_{\text {lum }}$ was positively correlated with $\mathrm{BMD}_{\text {neck }}(r=0.618)$.

The median volumes of removed adenomas, $\mathrm{Ca}$ and iCa were slightly associated with iPTH $(r=0.466$, $r=0.420$ and $r=0.554$, respectively). Albumin, $24 \mathrm{hU}$ Ca and testosterone were neither correlated with $\mathrm{BMD}_{\text {neck }}$ ( $r=0.079, r=0.006$ and $r=0.096$, respectively) nor with osteocalcin ( $r=-0.036, r=0.227$ and $r=0.002$, respectively).

\section{Univariate, bivariate and multivariable analysis of risk factors for HBS}

An analysis of 25(OH)D two days before surgery, broken down according to seasonal measurement, showed significant differences with median values of 31.6 (IQR 19.2, 49.6) nmol/L in January-March vs 51.9 (IQR 34.5, 65.8) $\mathrm{nmol} / \mathrm{L}$ in July-September $(P<0.001)$. However,

\section{Figure 3}

Pre- and post-operative kinetics of iPTH levels among patients in group 1 (A) and group 2 (B). Preoperative iPTH levels were cut-off at $350 \mathrm{pg} / \mathrm{mL}$ for better visualization: 10 (30.3\%) patients in group 1 and 11 (3.2\%) in group 2 had iPTH levels $>350 \mathrm{pg} / \mathrm{mL}$ (max. $1106 \mathrm{pg} / \mathrm{mL}$ and $1550 \mathrm{pg} / \mathrm{mL}$ respectively) at day 0 .

univariate analysis of $25(\mathrm{OH}) \mathrm{D}$ failed to reveal an impact on HBS (c-index=0.587) with an OR of 0.55 (95\% CI, $0.14-2.22 ; P=0.388)$ by comparing July-September with January-March.

Univariate logistic regression of potential preoperative risk factors for HBS is shown in Table 2. With an OR of 9.50 (95\% CI 2.79-32.21; P<0.001), a decrease of iPTH of 90-100\% compared to 0-80\% was significantly associated with HBS (c-index $=0.738$ ).

Univariate logistic models adjusted for osteocalcin, BMDneck and 25(OH)D showed a significant relationship between iPTH and HBS (OR 2.09, 95\% CI, 1.47-2.97; $\mathrm{P}<0.001$ ) (Table 2). iPTH had the highest predictive value (c-index $=0.785$, 95\% CI, 0.693-0.877), followed by osteocalcin (c-index $=0.685,95 \% \mathrm{CI}, 0.567-0.804)$, BMDneck (c-index $=0.648, \quad 95 \% \quad$ CI, $0.550-0.745)$ and $25(\mathrm{OH}) \mathrm{D}$ (c-index $=0.576,95 \% \mathrm{CI}, 0.466-0.687$ ). Receiver-operating characteristic (ROC) curves are presented in Fig. 4.

Adjusting the univariate logistic models for osteocalcin (c-index =0.672) and BMDneck (c-index=0.651) with $25(\mathrm{OH}) \mathrm{D}$ did not increase the predictive performance 
Table 2 Univariate and multivariable logistic models of potential preoperative risk factors for HBS.

\begin{tabular}{l} 
Parameter \\
\hline Univariate logistic models \\
Ca \\
Magnesium \\
Albumin \\
$25(O H) D$ \\
iPTH \\
Osteocalcin \\
24 hU \\
BMD \\
BMD \\
Testosterone (men) \\
Adenoma volume \\
Multivariable logistic model \\
iPTH \\
Osteocalcin \\
BMD \\
25(OH)D
\end{tabular}

\begin{tabular}{l}
$n$ \\
\hline \\
385 \\
385 \\
385 \\
383 \\
385 \\
378 \\
374 \\
352 \\
355 \\
108 \\
382 \\
346
\end{tabular}

\begin{tabular}{c}
\hline 33rd percentile \\
\hline 2.77 \\
0.81 \\
43.6 \\
33.3 \\
145 \\
45.7 \\
9.76 \\
-2.1 \\
-1.6 \\
4.67 \\
7.84 \\
143 \\
45.6 \\
-1.6 \\
34.0
\end{tabular}

\begin{tabular}{c} 
66th percentile (reference) \\
\hline \\
2.64 \\
0.87 \\
46.3 \\
50.8 \\
96 \\
30.4 \\
6.15 \\
-1.0 \\
-0.7 \\
3.65 \\
2.93 \\
97 \\
30.0 \\
-0.7 \\
50.6
\end{tabular}

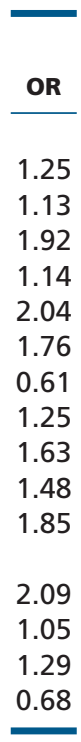

\begin{tabular}{l}
\hline \multicolumn{2}{c}{$\mathbf{9 5 \%} \mathbf{C l}$} \\
\hline Lower \\
\hline \\
1.00 \\
0.91 \\
1.45 \\
0.82 \\
1.60 \\
1.38 \\
0.41 \\
0.91 \\
1.17 \\
1.04 \\
1.35 \\
\\
1.47 \\
0.73 \\
0.90 \\
0.46 \\
\hline
\end{tabular}

Odds ratios (OR) are given comparing a patient at the 33rd percentile with another patient at the 66th percentile (reference). Reading example: A patient with preoperative $\mathrm{Ca}$ of $2.77 \mathrm{mmol} / \mathrm{L}$ (equaling the $33 \mathrm{rd}$ percentile) has an OR of 1.25 with a $95 \% \mathrm{Cl}$ of $1.00-1.56$ compared to another patient with preoperative $\mathrm{Ca}$ of $2.64 \mathrm{mmol} / \mathrm{L}$.

of either model (osteocalcin c-index $=0.679$, BMDneck c-index $=0.649$ respectively; data not shown).

\section{Discussion}

The results of the present study document that $8.6 \%$ of the patients with sporadic PHPT developed HBS after removal of a solitary parathyroid adenoma. Irrespective of seasonal differences, 25(OH)D deficiency did not influence its occurrence. A high preoperative level of iPTH (median $256 \mathrm{pg} / \mathrm{mL}$ vs $110 \mathrm{pg} / \mathrm{mL}$ ) was strongly associated with HBS, whereas there was no association between osteocalcin and $\mathrm{BMD}_{\text {neck }}$ in the multivariable analysis.

The incidence of HBS in this study is in accordance with the findings of Brasier et al. (10) who documented HBS in $12.6 \%$. Other smaller case series $(6,18,19)$ have found incidences between $4 \%$ and $90 \%$. In a case report authored by Graal et al. (20), short preoperative treatment with pamidronate and vitamin $D$ supplementation failed to inhibit postoperative development of HBS. Preoperatively depleted levels of 25(OH)D have been variously discussed to be a risk factor for HBS $(12,13,21,22)$. The hypothesis of HBS development is based on skeleton demineralization due to low circulating levels of $1,25(\mathrm{OH}) 2 \mathrm{D}$, leading postoperatively to an increased skeletal Ca requirement (11). However, multivariable analyses were not performed in any of the aforementioned studies and two studies were based on 'clinical symptoms' without postoperative Ca measurements $(12,13)$. Another prospective investigation explored only 25(OH)D as a risk factor for HBS in patients who were treated with 1-alpha-hydroxy-vitamin D3 before surgery (21). In the present study, 25(OH)D was not shown to be a significant risk factor for the development of HBS, neither in univariate nor in multivariable analysis. Furthermore, we did not identify an association between $25(\mathrm{OH}) \mathrm{D}$ and serum markers of bone turnover or $\mathrm{BMD}_{\text {neck, }}$, which may have supported the hypothesis of an impact

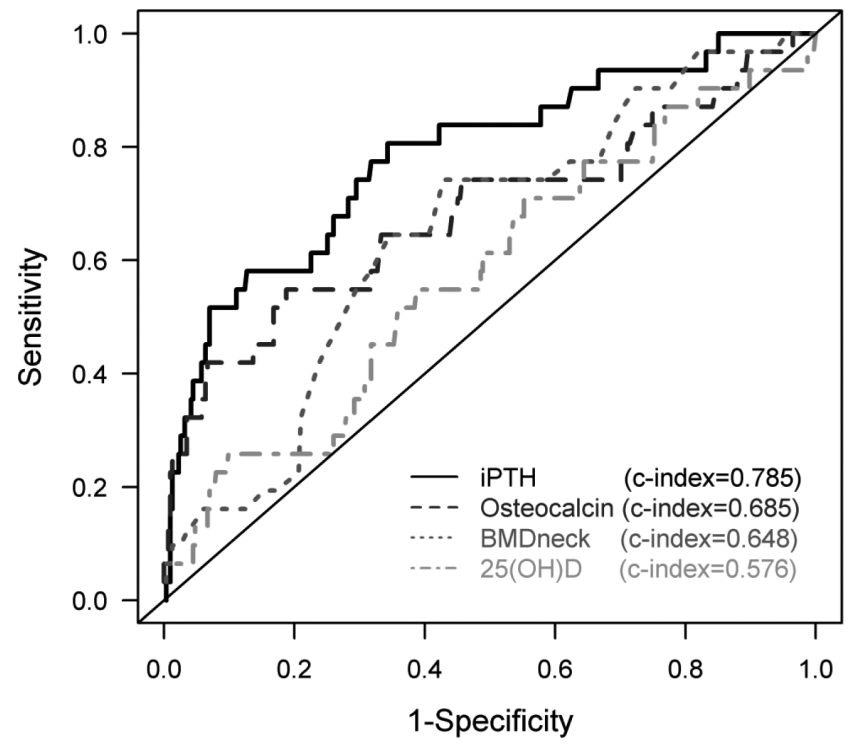

Figure 4

ROC curves based on univariate logistic regression for $\mathrm{PPTH}$, osteocalcin, $\mathrm{BMD}_{\text {neck }}$ and 25(OH)D on HBS. 
of $25(\mathrm{OH}) \mathrm{D}$ deficiency on skeleton mineralization and indirectly on HBS (11). Although the results of Press et al. (23) require cautious interpretation due to systematic postoperative treatment with oral $\mathrm{Ca}$, the incidence and timing of hypocalcemia symptoms were, similarly to our study, independent of 25(OH)D after surgery.

As associations of 25(OH)D deficiency with secondary hyperparathyroidism and hyperproliferation of parathyroid cells have been described, a correlation analysis of preoperative $25(\mathrm{OH}) \mathrm{D}$ with $\mathrm{iPTH}$ and the median volume of removed adenoma was performed and produced no significant results $(2,15)$.

The present univariate analysis confirmed the risk factors for HBS discussed in literature $(11,21,24,25$, 26), such as high Ca, ALP and osteocalcin levels, as well as a large median volume of the hyperfunctioning parathyroid gland. However, other studies $(27,28)$ found no evidence for the aforementioned HBS risk factors. Likewise, the current multivariable logistic model revealed high preoperative iPTH levels as the only significant risk factor for HBS. In accordance with the study of Brasier and Nussbaum (11), patients with HBS presented preoperative iPTH levels that were increased by more than twofold.

Some of the risk factors, such as iPTH and $\mathrm{Ca}$, were associated in the correlation analysis. This finding has also been documented by Nasiri et al. (29) and explained as increased $\mathrm{Ca}$ (re-)absorption from bone and renal tubules in case of elevated iPTH levels (2). The studies by Zamboni and Folse (8) and Brasier and Nussbaum (11) identified the volume of the removed parathyroid gland as a predictive value. This finding may be explained by the current association between iPTH and the volume of removed adenoma. Likewise, Nasiri et al. (29) found a strong correlation between higher levels of preoperative iPTH and heavier and larger adenoma in PHPT.

Several investigations have reported radiological evidence of PHPT-related bone manifestation, such as cysts and brown tumors, bone erosions or phalanx resorption, as risk factors for $\operatorname{HBS}(19,21,22,30)$. In an attempt to evaluate this finding, we used preoperative $\mathrm{BMD}_{\text {neck }}$ as an objective comparison parameter. $\mathrm{BMD}_{\text {neck }}$ was a significant risk factor for the development of HBS in univariate, but not in the multivariable analysis. It has been argued that BMD may be an imperfect marker, as BMD changes occur slowly (7). Moreover, ostecalcin had no significant impact on the development on HBS in multivariable analysis, although osteocalcin has been reported to be a specific serum marker of bone (7).

Testosterone is known to stimulate renal Ca transport and therefore the $\mathrm{Ca}$ excretion (31). In the current univariate analysis, high levels of testosterone in males (median $5.07 \mathrm{pg} / \mathrm{mL}$ in group $1 \mathrm{vs} 4.14 \mathrm{pg} / \mathrm{mL}$ in group 2) were a significant risk factor for HBS. On the other hand, univariate analysis revealed an inverse correlation between $24 \mathrm{hU}_{\mathrm{Ca}}$ and HBS.

Brasier and Nussbaum (11) identified low magnesium and albumin levels in patients with HBS. Low serum magnesium is particularly found in patients with advanced bone disease in PHPT (32). While magnesium was not associated with HBS, a decreased albumin proved to be a significant risk factor in our univariate analysis. The rationale for the latter remains unclear. A possible explanation may be the finding of Afshinnia et al. (33), listing hypoalbuminemia as an independent risk factor for osteoporosis. Possible reasons include an activation of osteoclasts, suppression of osteogenesis and change of the metabolism of iPTH and vitamin D-binding protein (33). However, we found no correlation between albumin and $\mathrm{BMD}_{\text {neck }}$ or osteocalcin.

Postoperative HBS leads to a requirement of $\mathrm{Ca}$ and vitamin D supplementation (34). According to the present analysis of risk factors, postoperative HBS cannot be predicted preoperatively. The definite diagnosis can only be made by measuring $\mathrm{Ca}$ and iPTH after postoperative day 4 (between postoperative day 5 and 7). Mildly symptomatic postoperative hypocalcemia due to HBS can be prevented by a postoperative supplementation of $\mathrm{Ca}$ and 25-hydroxycholecalciferol (1000 mg/880IE) in combination with 1,25-dihydroxycholecalciferol (calcitriol; $0.25 \mu \mathrm{g}$ ) twice a day.

We recommend a laboratory control 8 weeks postoperatively to re-evaluate the parathyroid metabolism and to reappraise the requirement of $\mathrm{Ca}$ and vitamin substitution.

To our knowledge, this is the largest study of its kind by analyzing 385 highly selected patients for all relevant HBS risk factors discussed in literature, along with consistent postoperative biochemical $\mathrm{Ca}$ and $\mathrm{iPTH}$ measurements. Furthermore, it is the first study to simultaneously evaluate the predictive value of preoperative $25(\mathrm{OH}) \mathrm{D}$ and different bone markers, such as osteocalcin, betacrosslaps, P1NP, BAP, $\mathrm{BMD}_{\text {lumb }}$ and $\mathrm{BMD}_{\text {neck }}$. BMD of the radius is not shown in the present study. However, it was routinely measured and had a positive correlation with $\mathrm{BMD}_{\text {lumb }}$ and $\mathrm{BMD}_{\text {neck }}$. 25(OH)D levels were rather high in the present study population. Nevertheless, in all patients, preoperative vitamin D supplementation in the last three months was excluded by anamnesis. As HBS occurs in approximately $10 \%$ of the patients only, multivariable analysis could only be performed for a limited number 
of parameters, namely iPTH, osteocalcin, $\mathrm{BMD}_{\text {neck }}$ and $25(\mathrm{OH}) \mathrm{D}$, thus yielding restricted explanatory power.

In conclusion, the present study revealed no relationships between preoperative $25(\mathrm{OH}) \mathrm{D}$ deficiency, HBS and severity of metabolic bone disease, respectively, nor with iPTH or size of parathyroid adenoma. The only significant risk factor for the development of HBS in multivariable analysis was a high level of preoperative iPTH, which was increased by more than twofold compared to patients without HBS and showed associations with $\mathrm{Ca}$ levels and volumes of removed adenoma. Preoperative and intraoperative parameters are unable to indicate HBS. Therefore, we suggest a consistent postoperative $\mathrm{Ca}$ and vitamin $\mathrm{D}$ supplementation as cost-effective approach to restore a 'normal' bone metabolism.

\section{Declaration of interest}

The authors declare that there is no conflict of interest that could be perceived as prejudicing the impartiality of the clinical study reported.

\section{Funding}

This research did not receive any specific grant from any funding agency in the public, commercial or not-for-profit sector.

\section{Author contribution statement}

R M K and B N designed the study. R M K, P R, A S, C S and B N cared for the patients and obtained clinical information. $R M K$ and $D D$ analyzed the data. R M K wrote the first draft of the manuscript. All authors contributed to the interpretation of the data and writing of the manuscript, and approved the final version of the manuscript.

\section{References}

1 Niederle B, Stamm L, Langle F, Schubert E, Woloszczuk W \& Prager R. Primary hyperparathyroidism in Austria: results of an 8-year prospective study. World Journal of Surgery 199216 777-782; discussion 782-773. (https://doi.org/10.1007/BF02067385)

2 Bilezikian JP, Marcus R, Levine MA, Marcocci C, Silverberg SJ \& Potts JT. The Parathyroids: Basic and Clinical Concepts, 2015 Academic Press: Sam Diego, USA.

3 Riss P, Kaczirek K, Heinz G, Bieglmayer C \& Niederle B. A 'defined baseline' in PTH monitoring increases surgical success in patients with multiple gland disease. Surgery 2007142 398-404. (https://doi. org/10.1016/j.surg.2007.05.004)

4 Debruyne F, Delaere P, Ostyn F, Van den Bruel A \& Bouillon R. Daily follow-up of serum parathyroid hormone and calcium after surgery for primary hyperparathyroidism. Journal of Otolaryngology 199928 305-308.

5 Debruyne F, Delaere P \& Vander Poorten V. Postoperative course of serum parathyroid hormone and calcium after surgery for primary hyperparathyroidism. Acta Oto-Rhino-Laryngologica Belgica 200155 153-157.

6 Witteveen JE, van Thiel S, Romijn JA \& Hamdy NA. Hungry bone syndrome: still a challenge in the post-operative management of primary hyperparathyroidism: a systematic review of the literature. European
Journal of Endocrinology 2013168 R45-R53. (https://doi.org/10.1530/EJE12-0528)

7 Rianon N, Alex G, Callender G, Jimenez C, Hu M, Grubbs E, Moreno M, Wathoo C, Petak S \& Perrier N. Preoperative serum osteocalcin may predict postoperative elevated parathyroid hormone in patients with primary hyperparathyroidism. World Journal of Surgery 201236 1320-1326. (https://doi.org/10.1007/s00268-012-1432-4)

8 Zamboni WA \& Folse R. Adenoma weight: a predictor of transient hypocalcemia after parathyroidectomy. American Journal of Surgery 1986152 611-615. (https://doi.org/10.1016/0002-9610(86)90436-8)

9 Strickland PL \& Recabaren J. Are preoperative serum calcium, parathyroid hormone, and adenoma weight predictive of postoperative hypocalcemia? American Surgeon 200268 1080-1082.

10 Hollis BW. Circulating 25-hydroxyvitamin D levels indicative of vitamin D sufficiency: implications for establishing a new effective dietary intake recommendation for vitamin D. Journal of Nutrition 2005135 317-322.

11 Brasier AR \& Nussbaum SR. Hungry bone syndrome: clinical and biochemical predictors of its occurrence after parathyroid surgery. American Journal of Medicine 198884 654-660. (https://doi. org/10.1016/0002-9343(88)90100-3)

12 Lang BH \& Lo CY. Vitamin D3 deficiency is associated with lateonset hypocalcemia after minimally invasive parathyroidectomy in a vitamin D borderline area. World Journal of Surgery 201034 1350-1355. (https://doi.org/10.1007/s00268-009-0377-8)

13 Stewart ZA, Blackford A, Somervell H, Friedman K, Garrett-Mayer E, Dackiw AP \& Zeiger MA. 25-Hydroxyvitamin D deficiency is a risk factor for symptoms of postoperative hypocalcemia and secondary hyperparathyroidism after minimally invasive parathyroidectomy. Surgery 2005138 1018-1025; discussion 1025-1016. (https://doi. org/10.1016/j.surg.2005.09.018)

14 Rolighed L, Rejnmark L, Sikjaer T, Heickendorff L, Vestergaard P, Mosekilde L \& Christiansen P. Vitamin D treatment in primary hyperparathyroidism: a randomized placebo controlled trial. Journal of Clinical Endocrinology and Metabolism 201499 1072-1080. (https:// doi.org/10.1210/jc.2013-3978)

15 Untch BR, Barfield ME, Dar M, Dixit D, Leight GS Jr \& Olson JA Jr. Impact of 25-hydroxyvitamin D deficiency on perioperative parathyroid hormone kinetics and results in patients with primary hyperparathyroidism. Surgery 2007142 1022-1026. (https://doi. org/10.1016/j.surg.2007.09.026)

16 Wilhelm SM, Wang TS, Ruan DT, Lee JA, Asa SL, Duh QY, Doherty GM, Herrera MF, Pasieka JL, Perrier ND et al. The American association of endocrine surgeons guidelines for definitive management of primary hyperparathyroidism. JAMA Surgery 2016151 959-968. (https://doi.org/10.1001/jamasurg.2016.2310)

17 Bilezikian JP, Brandi ML, Eastell R, Silverberg SJ, Udelsman R, Marcocci C \& Potts JT Jr. Guidelines for the management of asymptomatic primary hyperparathyroidism: summary statement from the Fourth International Workshop. Journal of Clinical Endocrinology and Metabolism 201499 3561-3569. (https://doi.org/10.1210/jc.20141413)

18 Malabu UH \& Founda MA. Primary hyperparathyroidism in Saudi Arabia: a review of 46 cases. Medical Journal of Malaysia 200762 394-397.

19 Agarwal G, Mishra SK, Kar DK, Singh AK, Arya V, Gupta SK \& Mithal A. Recovery pattern of patients with osteitis fibrosa cystica in primary hyperparathyroidism after successful parathyroidectomy. Surgery 2002 132 1075-1083; discussion 1083-1075. (https://doi.org/10.1067/ msy.2002.128484)

20 Graal MB \& Wolffenbuttel BH. Consequences of long-term hyperparathyroidism. Netherlands Journal of Medicine 199853 37-42. (https://doi.org/10.1016/S0300-2977(98)00010-2)

21 Heath DA, Van't Hoff W, Barnes AD \& Gray JG. Value of 1-alphahydroxy vitamin D3 in treatment of primary hyperparathyroidism 
before parathyroidectomy. BMJ 19791 450-452. (https://doi. org/10.1136/bmj.1.6161.450)

22 Raef H, Ingemansson S, Sobhi S, Sultan A, Ahmed M \& Chaudhry M. The effect of vitamin D status on the severity of bone disease and on the other features of primary hyperparathyroidism (pHPT) in a vitamin D deficient region. Journal of Endocrinological Investigation 200427 807-812. (https:// doi.org/10.1007/BF03346273)

23 Press D, Politz D, Lopez J \& Norman J. The effect of vitamin D levels on postoperative calcium requirements, symptomatic hypocalcemia, and parathormone levels following parathyroidectomy for primary hyperparathyroidism. Surgery 2011150 1061-1068. (https://doi. org/10.1016/j.surg.2011.09.018)

24 Spiegel AM, Marx SJ, Brennan MF, Brown EM, Downs RW Jr, Gardner DG, Attie MF \& Aurbach GD. Parathyroid function after parathyroidectomy: evaluation by measurement of urinary cAMP. Clinical Endocrinology 198115 65-73. (https://doi. org/10.1111/j.1365-2265.1981.tb02749.x)

25 Westerdahl J, Lindblom P, Valdemarsson S, Tibblin S \& Bergenfelz A. Risk factors for postoperative hypocalcemia after surgery for primary hyperparathyroidism. Archives of Surgery 2000135 142-147. (https:// doi.org/10.1001/archsurg.135.2.142)

26 Loke SC, Tan AW, Dalan R \& Leow MK. Pre-operative serum alkaline phosphatase as a predictor for hypocalcemia post-parathyroid adenectomy. International Journal of Medical Sciences 20129 611-616. (https://doi.org/10.7150/ijms.4861)

27 Lee IT, Sheu WH, Tu ST, Kuo SW \& Pei D. Bisphosphonate pretreatment attenuates hungry bone syndrome postoperatively in subjects with primary hyperparathyroidism. Journal of Bone and
Mineral Metabolism 200624 255-258. (https://doi.org/10.1007/ s00774-005-0680-x)

28 Mittendorf EA, Merlino JI \& McHenry CR. Post-parathyroidectomy hypocalcemia: incidence, risk factors, and management. American Surgeon 200470 114-119; discussion 119-120.

29 Nasiri S, Sorush A, Mehrkhani F \& Hedayat A. Could we predict adenoma weight and postoperative serum calcium level with preoperative serum biochemical markers in patients with primary hyperparathyroidism?. Internet Journal of Surgery 200716 1-5.

30 Ajmi S, Sfar R, Trimeche S, Ben Ali K \& Nouira M. Scintigraphic findings in hungry bone syndrome following parathyroidectomy. Revista Española de Medicina Nuclear 201029 81-83. (https://doi. org/10.1016/j.remn.2009.10.003)

31 Hsu YJ, Dimke H, Schoeber JP, Hsu SC, Lin SH, Chu P, Hoenderop JG \& Bindels RJ. Testosterone increases urinary calcium excretion and inhibits expression of renal calcium transport proteins. Kidney International 201077 601-608. (https://doi.org/10.1038/ki.2009.522)

32 Jones CT, Sellwood RA \& Evanson JM. Symptomatic hypomagnesaemia after parathyroidectomy. BMJ 19733 391-392. (https://doi.org/10.1136/bmj.3.5876.391)

33 Afshinnia F \& Pennathur S. Association of hypoalbuminemia with osteoporosis: analysis of the national health and nutrition examination survey. Journal of Clinical Endocrinology and Metabolism 2016101 2468-2474. (https://doi.org/10.1210/jc.2016-1099)

34 Kerschan-Schindl K, Riss P, Krestan C, Rauner M, Bieglmayer C, Gleiss A, Fialka-Moser V, Niederle B \& Pietschmann P. Bone metabolism in patients with primary hyperparathyroidism before and after surgery. Hormone and Metabolic Research 201244 476-481. (https://doi.org/10.1055/s-0032-1308998)

Received 21 May 2017

Revised version received 28 August 2017

Accepted 6 September 2017 